\title{
EVENTS
}

\section{Summary Report of the Seventh Geneva Conference on Person- centered Medicine}

\author{
Report prepared by Juan E. Mezzich, James Appleyard, Michel Botbol, Tesfa Ghebrehiwet, \\ Joanna Groves, Ihsan Salloum and Sandra van Dulmen, on behalf of the Board of the \\ International College of Person Centered Medicine.
}

\begin{abstract}
On April 28-30, 2014, the Seventh Geneva Conferences took place at Geneva University Hospital and the World Health Organization Headquarters. It built on previous annual Geneva Conferences since 2008 [1, 2], from which emerged the International Network, now International College, of Person Centered Medicine [3, 4].

The Seventh Geneva Conference was organized by the International College of Person-centered Medicine (ICPCM) in collaboration with the World Medical Association (WMA), the World Health Organization (WHO), the International Alliance of Patients' Organizations (IAPO), the International Council of Nurses ICN), the International Foundation for Integrated Care (IFIC), the International Federation of Social Workers (IFSW), the International Pharmaceutical Federation (FIP), the World Federation for Mental Health (WFMH), the Council for International Organizations of Medical Sciences (CIOMS), the International College of Surgeon's (ICS), the International Federation of Gynecology and Obstetrics (FIGO), the Medical Women's International Association (MWIA), the International Federation for Ageing (IFA), the World Association for Sexual Health (WAS), the European Federation of Associations of Families of People with Mental Illness (EUFAMI), the World Federation for Medical Education (WFME), the International Association of Medical Colleges (IAOMC), the Paul Tournier Association, the World Association for Dynamic Psychiatry (WADP), the European Association for Communication in Health Care (EACH), L'Observatoire de Medecine de la Personne, the WHO Collaborating Center at Imperial College London, the International Francophone Psychiatric Federation (ALFAPSY), the French Psychiatric Association, the International Federation of Medical Students' Associations (IFMSA), the Zagreb University Medical School, the Peruvian University Cayetano Heredia, Francisco de Vitoria University, the Universite de Bretagne Occidentale, the Medical University of Plovdiv, the Belgrade University Institute of Mental Health, and University of Buckingham Press, with the auspices of the Geneva University Medical School and Hospital.

The Conference Organizing Committee was composed of James Appleyard (President, International College of Person Centered Medicine), Juan E. Mezzich (Secretary General, International College of Person Centered Medicine), Michel Botbol, Tesfamicael Ghebrehiwet, Jo Groves, Ihsan Salloum, and Sandra Van Dulmen (all Board Members of the International College of Person Centered Medicine), Edward Kelley and Hernan Montenegro (World Health Organization), and Lourdes Ferrer and Nick Goodwin (International Foundation for Integrated Care).

Financial or in-kind support for the Conference was provided by 1) the International College of Person-centered Medicine (core funding), 2) the University of Geneva Medical School (auditorium services and coffee breaks), 3) the Paul Tournier Association (conference dinner, secretarial support and printing of the conference booklet and badges), 4) the World Health Organization (support for a special session at WHO headquarters), (5) The World Medical Association (technical support), and 6) Participants' registration fees.

Under the overall theme of Person- and People-Centered Integrated Care for All, the Seventh Geneva Conference encompassed a number of lectures, plenary symposia, teaching workshops, presentations by younger researchers with senior panel feedback, brief oral presentations, and poster presentations. Additionally, pre-conference institutional work meetings involving special institutional projects were held prior to the core conference.
\end{abstract}

\section{Pre-Conference Work Meetings}

The Work Meetings took place in the afternoon of April 27. They dealt with an initial presentation and discussion of a draft of the 2014 Geneva Declaration, an update and further work on Person-centered Diagnosis, update and advancement on Guiding Principles for Person-centered Clinical Care, a report on the Books Program, and a proposal for a WFMH Global Program to Advance Person- and People-centered Mental Health.

\section{Meeting of the ICPCM Board}

A meeting of the ICPCM Board also took place the afternoon of April 27. It included a last minute review of the 7th Geneva Conference, appreciation for the advanced draft of the 2014 Geneva Declaration, a discussion of the evolving WHO Strategy for People-centered Integrated Health Services, review of the Post-Zagreb Congress reports, planning of the 2nd 
International Congress of Person Centered Medicine in Buenos Aires, preliminary planning of the 8th Geneva Conference, and preparations for the 2014 General Assembly.

\section{LtoR: J E Mezzich, J Groves, J Appleyard, M Botbol, S Van Dulmen, and T Ghebrehiwet at the ICPCM Board Meeting, $7^{\text {th }}$ Geneva Conference, April 27, 2014.}

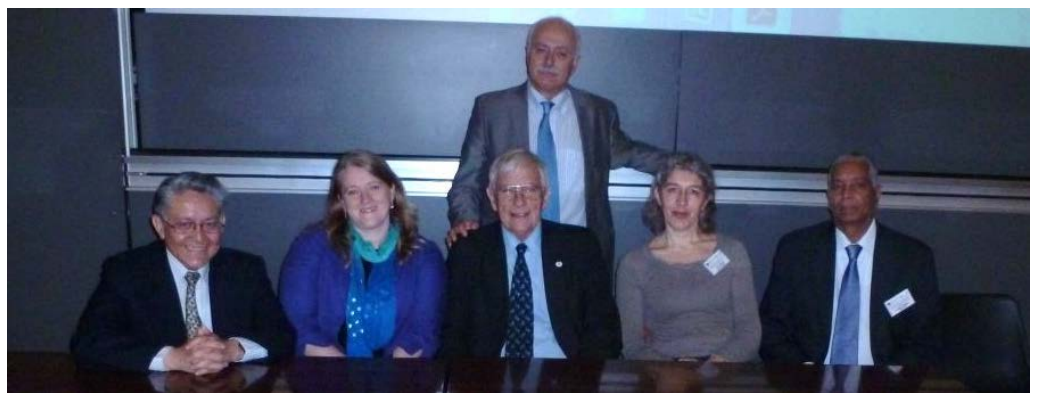

\section{Meeting of the Editorial Board of the International J ournal of Person Centered Medicine}

This meeting of the Editorial Board of the Journal was attended by Editorial Board members as well as ICPCM Board members. It included a report on Journal activities involving collaboration among the editorial leadership, editorial reviewers, and the University of Buckigham Press. Commitment to the Journal was reaffirmed by all present.

\section{General Assembly of the International College of Person Centered Medicine}

The General Assembly took place the evening of April 28. It was opened by the ICPCM President, Prof. Jim Appleyard, in the company of the ICPCM Board. A list of I ICPCM Foundational Fellows was shown and those present in the auditorium were recognized and congratulated by the Assembly. A Memorial Act was conducted for Foundational Fellows Dr. Antoine Besse (France) and Prof. Jitendra Trivedi (India), with special words from Professors Michel Botbol and Roy Kallivayalil, respectively.

The President made a Brief Report on the past year's work of the ICPCM. He touched on the dedicated contributions of the Members of the Board through twelve monthly teleconferences and continuous communications, all administratively supported by our small secretariat. He highlighted the Geneva Conferences process and their emerging Geneva Declarations, our First International Congress in Zagreb in November 2013, the continuing publication of the International Journal of Person Centered Medicine, the preparation of an authoritative book on Person Centered Psychiatry, and ongoing projects on person centered diagnosis and person centered clinical care guiding princip.les The Assembly expressed appreciation for this report.

The President then presented on behalf of the Board the following action plan which was well received by the Assembly: a) Planning for the ICPCM Second International Congress in Buenos Aires, November 7-9, 2014, b) Organization of the 8th Geneva Conference on Person-centered Medicine in late April 2015 with its main theme being Person Centered Primary Health Care, c) Continued publication of the International Journal of Person Centered Medicine and exploration of new publication ventures such as a person centered medicine book, d) Continued development of ICPCM Projects on Person-centered Diagnosis and Clinical Care Guidelines, e) Continued production of ICPCM event-related Declarations, which are building a body of knowledge and are increasingly recognized, and f) Redesigning and enhancement of the ICPCM Website. Upon completion of the agenda, the President adjourned the General Assembly.

\section{Core Conference}

The Core Conference was opened on April 28 by Prof. Jim Appleyard, President of the International College of Person Centered Medicine (ICPCM), and Dr. Hernan Montenegro, WHO Department for Health Systems Governance and Policy. They were joined in the presidium by the members of the ICPCM Board of Directors.

A Keynote Lecture on person-centered and integrated care across the life-cycle by the ICPCM President proposed that the health and wellbeing of a person are adaptive processes related to the consequences of genetic, biological, social, cultural behavioral and economic determinants Circumstances change as the person develops with accumulative risk and protective factors especially during critical and sensitive periods. He emphasized that a life course perspective offers a more coherent approach with implications for long term health gain.

The first Plenary Symposium on Conceptual issues on health complexity and person-centered integrated care reviewed WHO perspectives on conceptualizing people-centered integrated care for all, philosophical considerations in approaching health complexity, the understanding of the principles and process of person-centered integrated care:, the engaging of 
complexity (from psychobiology to social systems), and integrating the complexity of human development in personcentered care.

LtoR: M Botbol, CW Van Staden, N Goodwin, H Montenegro, R Cloninger, J Appleyard, and J Snaedal, at the first plenary symposium of the $7^{\text {th }}$ Geneva Conference, April 28, 2014.

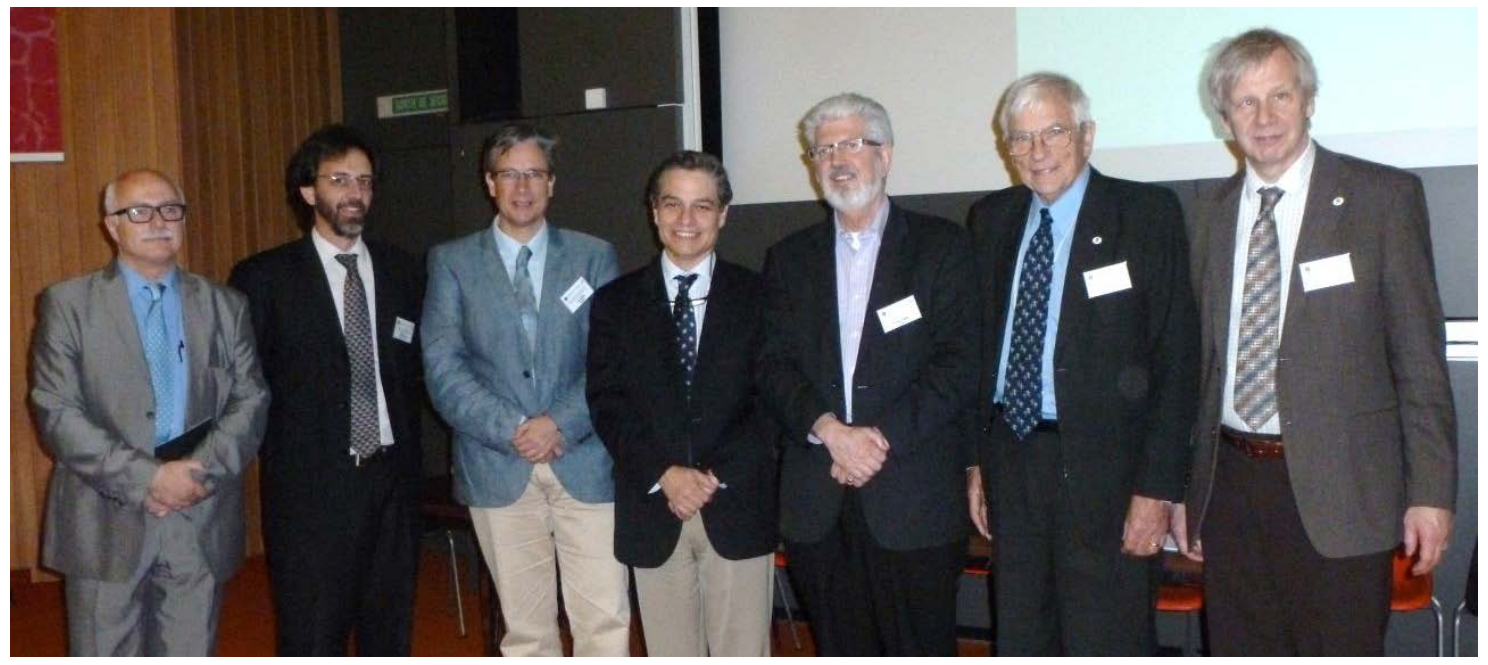

Highlights of a Posters Session on April 28 included presentations on a person-centered integral health self-evaluation from San Juan, Puerto Rico, and a person centered approach to patients with laryngeal cancer in Zagreb.

LtoR: Z Rakusic and A Krpan winners of a poster presentation award on April 28, 2014, at the $7^{\text {th }}$ Geneva Conference

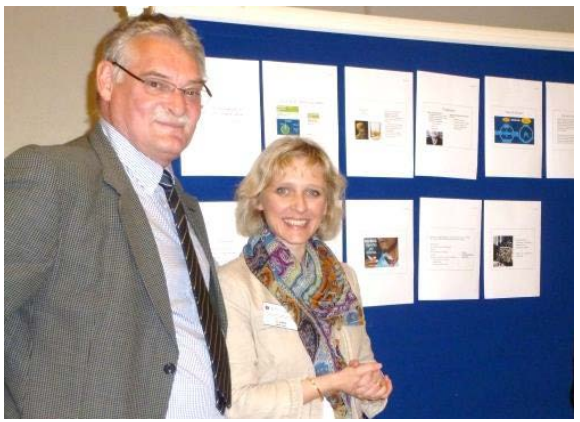

The Second Plenary Symposium focused on Communication for person- and people-centered integrated care. It considered patient perspectives on effective clinical communication, a person-centered integration of interdisciplinary teams involved, the importance of cultural and linguistic communication for person-centered integrated care, clinical communication research to support person-centered integrated care, and communication within the WHO Coordinated/Integrated Health Service Delivery Framework.

LtoR: R Bennegadi, S Van Dulmen, J Groves, R Wadoux, S Larchanche, V Djordjevic, V Stein, T Ghebrehiwet, and T Epperly at the Second Plenary Symposium of the $7^{\text {th }}$ Geneva Conference, April $28,2014$.

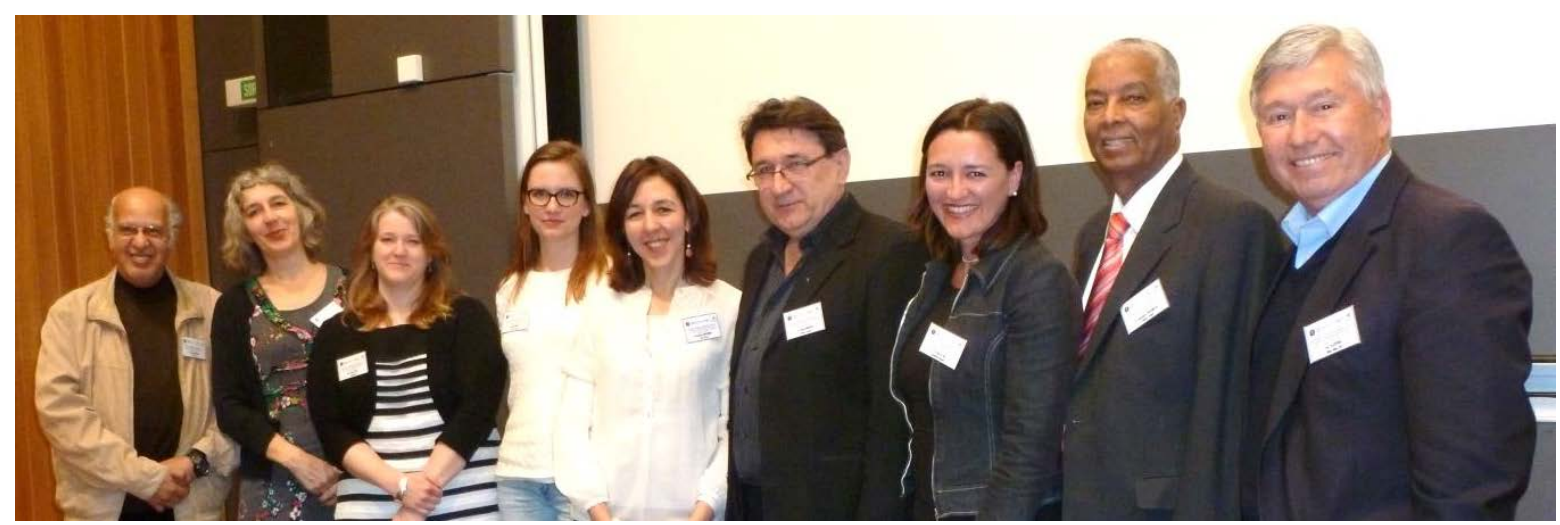


The Third Plenary Symposium of the Conference dealt with Diagnosis, treatment and care management for personcentered integrated care. It included discussions of principles, strategies, and prospects for person-centered diagnosis, palliative medicine as integrated care for all, and reviewed holistic assessment of needs, care management, and continuity in people centered integrated care.

\section{LtoR: N Goodwin, M Botbol, M Bras, and J E Mezzich at the Third Plenary Symposium of the $7^{\text {th }}$ Geneva Conference, April 28, 2014.}

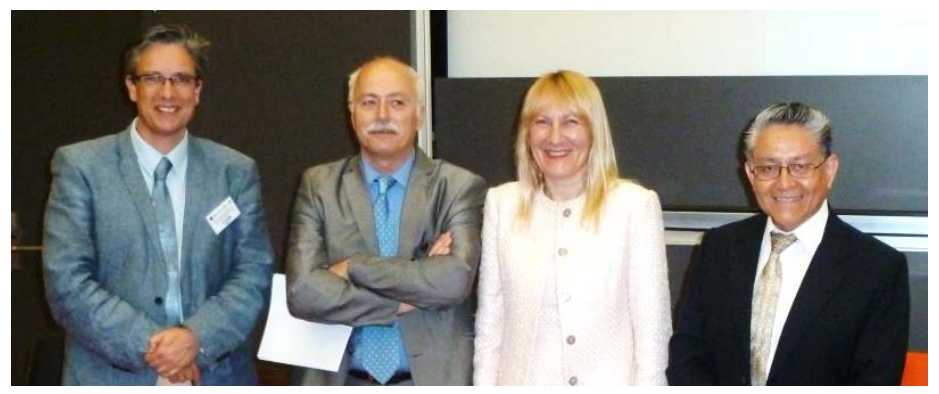

A Brief Oral Conceptual Presentations Session involved papers on “competent” medical practice to be person-centered and evidence-based, non-oncological supportive palliative care, multidisciplinary and multidimensional person-centered approaches for advanced heart failure patients, demographic challenges for person-centered medicine in the Czech Republic, and entrepreneurship as a path to empower impaired persons.

The First Teaching Workshop on Communication for Person-Centered Integrated Care presented topics on optimizing clinical communication, Spanish-speaking countries consensus on core curriculum of communication competencies in the medicine, teaching communication skills to medical students at Zagreb Univeristy, and knowledge and training needed for good communication in coordinated/integrated health service delivery.

The Second Teaching Workshop on Patient, Family and Community Engagement presented proposals for patient empowerment, family/caregiver involvement, and appropriate industry engagement.

The First Workgroups Meeting focused on the advancement of Person Centered Integrative Diagnosis. Its application in the Latin American Guide for Psychiatric Diagnosis (GLADP-VR) [5] was recognized. The upcoming validation of the GLADP-VR and the application of the PID model towards practical guides in general medicine were discussed.

In the Second Day of the Core Conference, the Fourth Plenary Symposium dealt with Public health and peoplecentered integrated care for all. The topics discussed were the emerging WHO Strategy on People-centered and Integrated Services; person-centered integrated care: what it is, and what is not; international examples of successful approaches integrating public health and people-centered integrated care, and the specific relevance of Andrija Stampar's legacy to person and people-centered integrated care for all.

\section{LtoR: H Montenegro, W Holzgreve, V Djordjevic, L Ferrer, N Goodwin, and L Salvador, at the Fourth Plenary Symposium of the $7^{\text {th }}$ Geneva Conference, April 29, 2014}

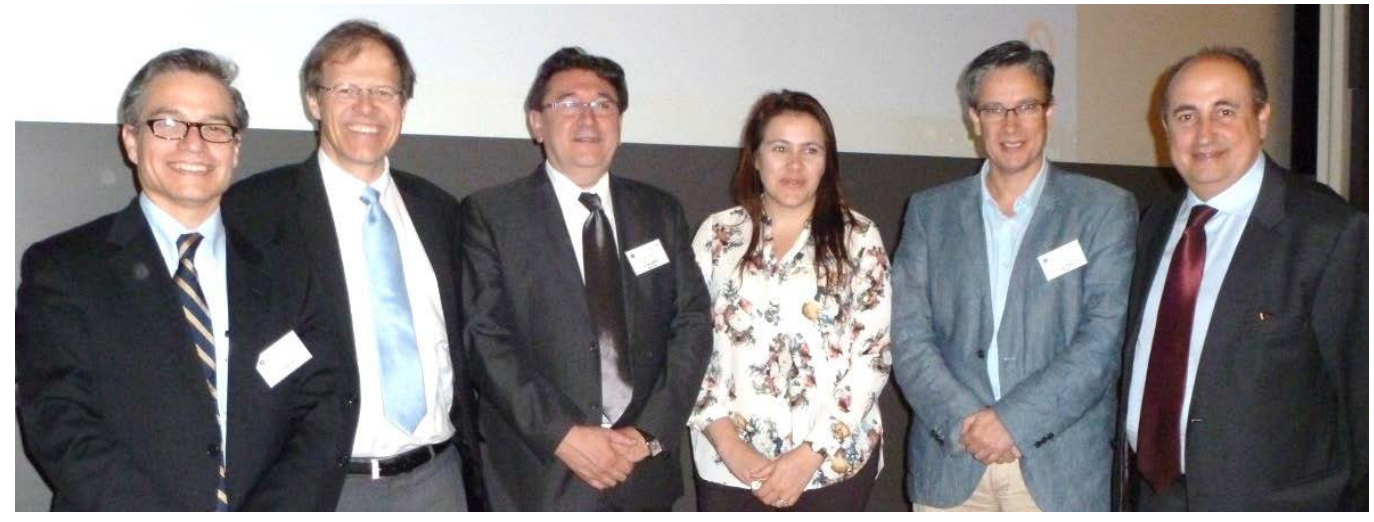

The Jitendra Trivedi Memorial Fifth Plenary Symposium on Education and training for person-centered integrated care involved presentations on person-centered undergraduate medical education for integrated care, person-centered residency training for integrated care, international experience with person-and people-centered health education, the place of the team approach for person-centered health care training, and competencies as an action area of the WHO Europe Coordinated/Integrated Health Services Delivery Framework. 
LtoR: J Appleyard, S Rawaf, L Ferrer, V Stein, R Kallivayalil, T Epperly, and T Ghebrehiwet, at the Fifth Plenary Symposium of the $7^{\text {th }}$ Geneva Conference, April 29, 2014.

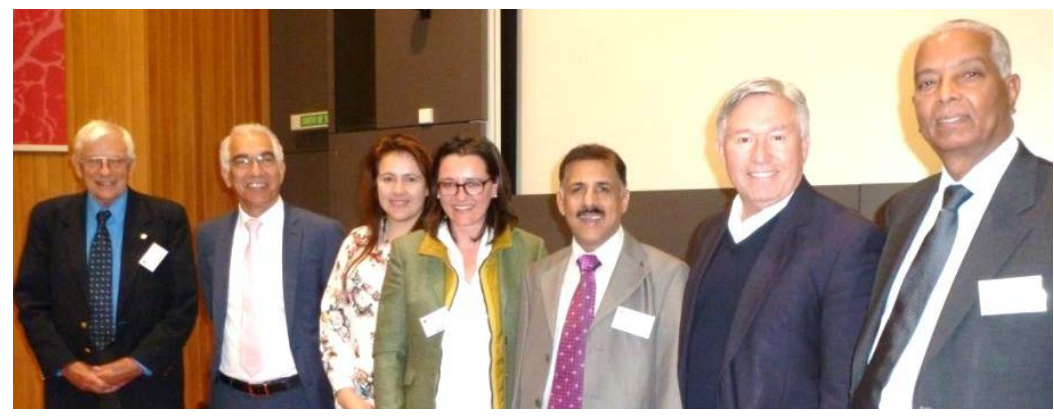

The Sixth Plenary Symposium touched on Metrics for person- and people-centered integrated care. Presentations were made on advancing the conceptualization and measurement of person-centered care, statistical approaches to scale development, refinement and validation, measuring the person's experience of integrated care, and conceptual and cultural strategies for the measurement of person-centered care.

LtoR: N Goodwin, Y Pongsupsp, CW Van Staden, J E Mezzich, L Kirisci, and L Salvador-Carulla at the Sixth Plenary Symposium of the $7^{\text {th }}$ Geneva Conference, April 29, 2014.

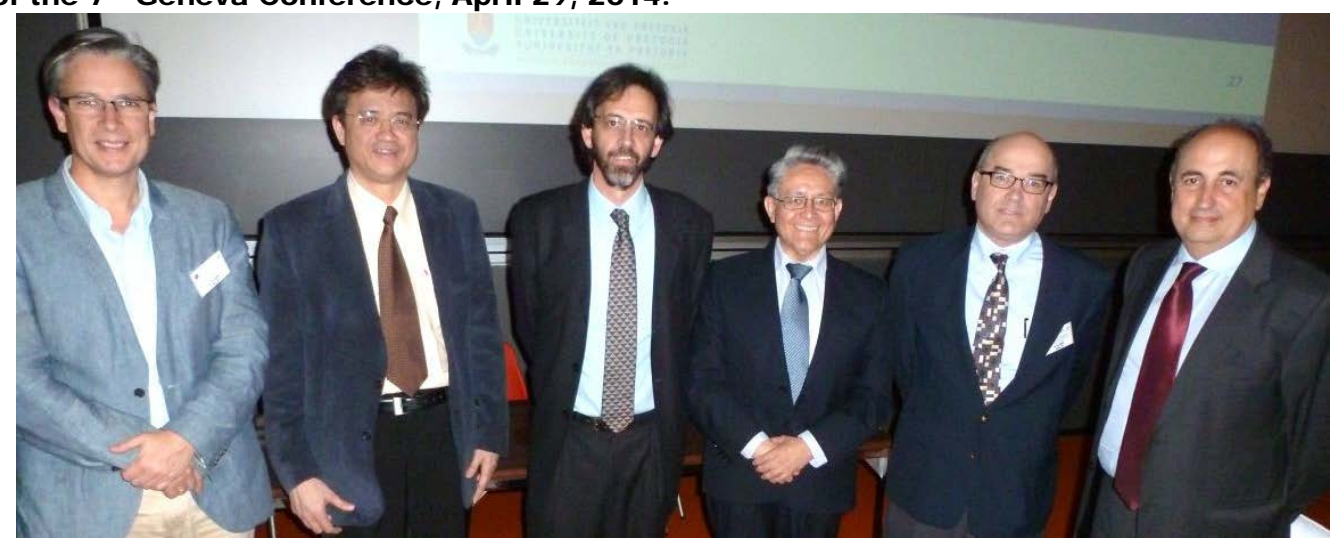

The Third Teaching Workshop on Person Centered Health Policies dealt with academic perspectives for developing person-centered health policies, policy as an action area of the WHO Coordinated/Integrated Health Service Delivery Framework, building central political narratives to support person-centered integrated care, and research and policy synergism for advancing people-centered care in Thailand.

The Fourth Teaching Workshop on Stakeholders for Person Centered Integrated Care involved the perspectives of patients, physicians, nurse perspectives, and pharmacists.

The Fifth Teaching Workshop on Psychotherapy in Person Centered Medicine, reviewed disclosure and apology with the person and family: a humanizing approach to medical error; Dynamic Psychiatry as an integrative psychiatric psychotherapeutic concept; and psychomotricity in person centered medicine.

The Second Workgroups Meeting on Person-centered Clinical Care Guiding Principles advanced the planning of the academic base of this project.

The Second Brief Oral Research Presentations focused on the hermeneutics of suffering, researching chronic pain, person centered medicine in modern pregnancy care, patient narratives in person-centered integrated care, and the work of a nutrition and obesity advisory centre.

The Sixth Teaching Workshop on Integrating Primary Care and Mental Health Care reviewed family medicine perspectives on integrating primary care and mental health care; multimorbidity in the severely mentally ill: the need for a person-centered integrated approach; integrated person-centered care for dementia; and international perspectives on integrated care.

The Seventh Teaching Workshop on Person-centered Child Healthcare discussed a patient-centered model for mental health screening in a pediatric allergy outpatient clinic, person-centered child health, and person-centered child and adolescent mental health.

The Third Workgroups Meeting advanced the finalization of the 2014 Geneva Declaration on Person- and PeopleCentered Integrated Care for All.

In the Third Day of the Core Conference, the Seventh Plenary Symposium on Ethical Bases for Person-Centered Integrated Care for All, included discussions on WMA's perspectives on ethics and person centered medicine, the ethics in 'patient-centered' care, and WHO's perspectives on integrating person-centered ethics into public health. 
LtoR: J Snaedal, MC Bouesseau, J E Mezzich, and J Appleyard at the Seventh Plenary Symposium of the $7^{\text {th }}$ Geneva Conference, April 30, 2014

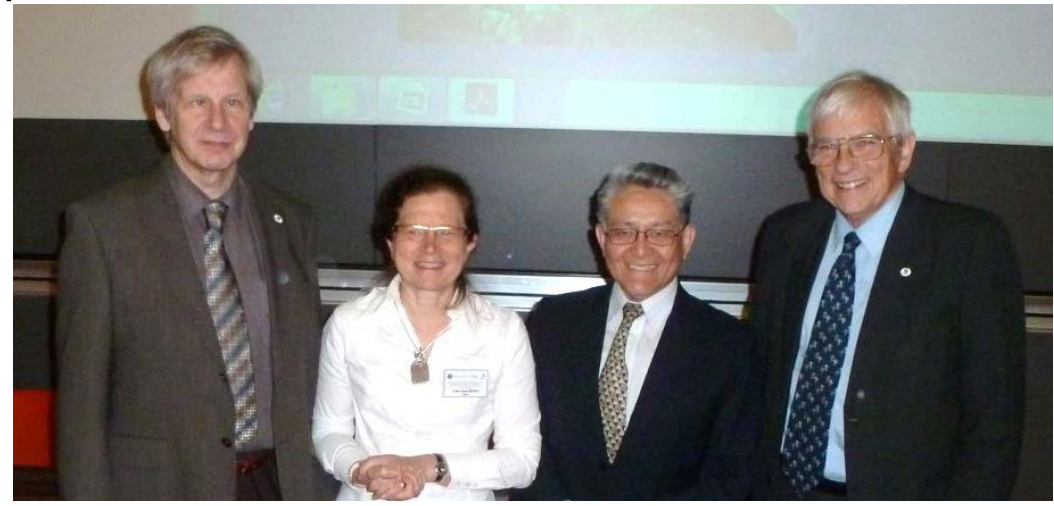

The Conference Closing included the presentation and adoption of the 2014 Geneva Declaration, conference concluding remarks, and an outline of next steps.

A Special Session with leaders of the ICPCM Cooperating Organizations and WHO officers at the WHO Headquarters was a colophon of the 7th Geneva Conference. The ICPCM-WHO collaboration originally took off on the basis of the 2009 World Health Assembly resolutions promoting people-centered care [6]. The discussions at this Special Session focused on cooperation for the development the WHO Strategy on People-Centered and Integrated Services [7]. As part of this, the director of the WHO Office of Service Delivery and Safety praised the ICPCM 2014 Geneva Declaration as a significant contribution to the development of the evolving WHO Strategy.

\section{Partial view of participants in the Special Session on WHO Strategy on People-Centered and Integrated Services at WHO Headquarters, April 30, 2014.}

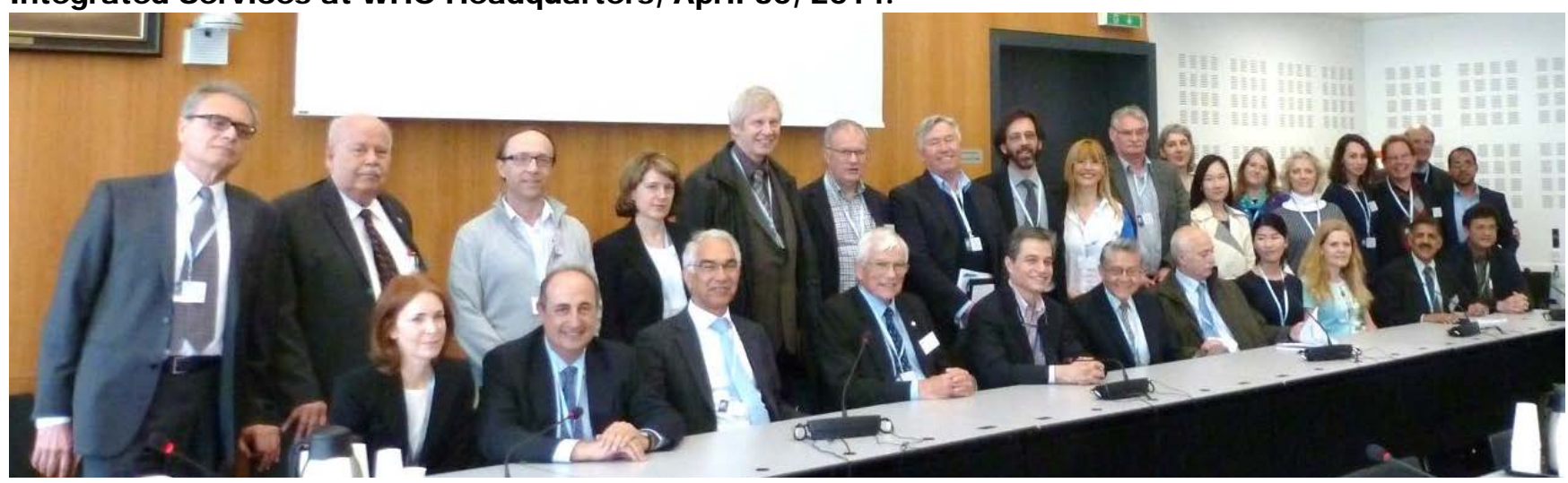

An Evaluation Survey of the $7^{\text {th }}$ Geneva Conference was carried out by mail after the conference. It yielded a number of recommendations for enhancing future events and suggested that the conference achieved outstanding overall quality through high level scientific presentations and discussions in a friendly atmosphere conducive to interdisciplinary and international networking.

\section{References}

[1]. Mezzich JE, Snaedal J, Van Weel C, Heath I (2010). Person-centered Medicine: A Conceptual Exploration. International Journal of Integrated Care, Supplement.

[2]. Mezzich JE, Snaedal J, van Weel C, Botbol M, Salloum IM (2011): Introduction to Person-centered Medicine: From Concepts to Practice. Journal of Evaluation in Clinical Practice 17: 330-332.

[3]. Mezzich JE, Snaedal J, van Weel C, Heath I (2009). The International Network for Person-centered Medicine: Background and First Steps. World Medical Journal 55: 104-107.

[4]. Mezzich JE (2012). The construction of person-centered medicine and the launching of an International College. International Journal of Person Centered Medicine 2: 6-10.

[5]. Asociación Psiquiátrica de América Latina (2013). Guía Latinoamericana de Diagnostico Psiquiátrico, Versión Revisada (GLADPVR). Lima: Author.

[6]. World Health Organization (2009). Resolution WHA62.12. Primary health care, including health system strengthening. In: SixtySecond World Health Assembly, Geneva, 18-22 May 2009. Resolutions and decisions. Geneva, 2009 (WHA62/2009/REC/1), Page 16.

[7]. World Health Organization (2013). Twelfth Global Program of Work 2014-2019. Geneva: Author. 